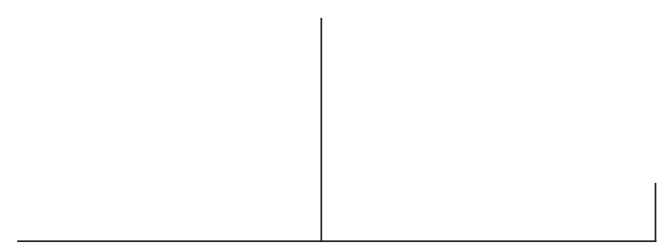

Rev. Latinoam. Psicopat. Fund., III, 1, 11-20

\title{
Psicanálise, educação e autismo: encontro de três impossíveis*
}

\author{
Lazslo A. Ávila
}

\begin{abstract}
Este artigo visa articular uma proposta para o trabalho clínico e pedagógico com sujeitos autistas. Parte da discussão dos três impossíveis apontados por Freud, ao qual se acrescenta a dimensão da ação frente ao autismo. Caracteriza os conceitos psicanalíticos que são instrumentais para essa clínica e os referenciais construtivistas que embasam as ações pedagógicas. Descreve o trabalho desenvolvido pela equipe multidisciplinar da Escola Municipal do Autista de São José do Rio Preto, SP, e conclui com considerações acerca do sentido envolvido em trabalhos dessa natureza.
\end{abstract}

Palavras-chave: Psicanálise, educação, autismo, instituição

\footnotetext{
Apresentado no Congresso Internacional sobre Austimo e Psicoses Infantis, realizado em São Paulo, de 8 a 10 de agosto de 1997.
} 


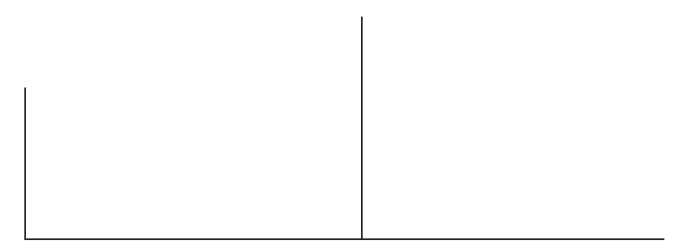

Freud, em "O mal-estar na civilização", anunciou as três profissões impossíveis: educar, governar e psicanalisar. Acrescentaríamos, por nossa conta e risco, o lidar com autistas como o quarto trabalho impossível.

$\mathrm{Na}$ intersecção dos impossíveis talvez seja possível ver desenhar-se, com contorno impreciso, uma prática clínicopedagógica voltada para sujeitos humanos marcados pela distância e pelo não-assujeitamento à cultura.

O autismo representa um tríplice desafio: para a psicanálise, para a educação e para as práticas sociais. Do ponto de vista da psicanálise uma série de questões se levanta quanto à própria definição do autismo, que não se enquadra como estrutura clínica neurótica ou psicótica, apresentando uma especificidade que diferentes gerações de psicanalistas (Kanner, Mahler, Bettelheim, Tustin, Meltzer, Alvarez, Jerusalinsky, Laznik-Penot, Lefort etc.) vêm tentando, com diferentes abordagens, caracterizar. O tratamento psicanalítico do autista vem apresentando impressivos resultados, embora sua gênese permaneça uma incógnita.

Do ponto de vista das práticas pedagógicas, o autismo é um campo aberto de interrogações e tentativas de acercamento e manejo; desde as práticas mais behavioristas até as recentes aproximações construtivistas, muitos trabalhos institucionais têm se voltado para a busca de métodos para educar ou ensinar o autista. 


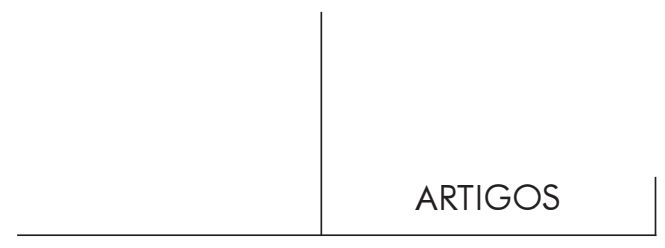

Socialmente o autista ocupa um “não-lugar”. Desinserido da produção e distribuição de bens, desalijado do consumo, não-participante das esferas políticas e dos movimentos sociais, esses indivíduos tendem a ser tomados por instituições que os "abrigam" e dirigem, não propiciando, contudo, via de regra, as condições para eles se manifestarem socialmente a partir de sua própria singularidade.

Confluindo os impossíveis do educar, do psicanalisar e do interagir com autistas, criamos uma instituição que, além de tudo, é pública: a Escola Municipal do Autista "Maria Lúcia de Oliveira”, de São José do Rio Preto, SP. Essa instituição, constituída por uma grande equipe multidisciplinar (53 profissionais), orientada por um projeto geral, embasado na psicanálise e no construtivismo, se propõe a atender quarenta crianças e adolescentes autistas e psicóticos, por quatro horas diárias, em dois períodos, mantendo uma estrutura de atenção multifatorial. Procuramos cumprir quatro funções básicas: atender, ensinar, transmitir e acompanhar.

O atendimento clínico dá-se nas áreas de Psicologia, Psiquiatria, Neurologia, Genética, Fisioterapia, Fonoaudiologia e Terapia Ocupacional. O ensino, com uma equipe de 12 professores, e sob uma coordenação pedagógica, utiliza os referenciais e a metodologia construtivista. A transmissão do que vamos aprendendo realiza-se em grupos de estudo, artigos, palestras, cursos e simpósios. Acompanhamos a equipe, o conjunto de crianças e a dinâmica institucional em um processo vivo de transformação dialética em que os sujeitos em interação e as práticas desenvolvidas dentro da instituição vão configurando as novas condições que gerarão as novas práticas que modificarão os sujeitos envolvidos. Estamos operando uma criação coletiva: uma instituição psicanalítico-construtivista para autistas.

Como comparece a psicanálise na organização dessa instituição? Organiza tarefas, dirige a filosofia de ação e dá os parâmetros para a definição das práticas institucionais. Estamos em um processo aberto de construção que ainda indaga sobre seus fundamentos e suas finalidades, mas que elegeu a psicanálise como seu campo de referência. As seguintes concepções são alguns dos dados com os quais buscamos nortear nosso trabalho.

Donald Meltzer (1979), dirigindo um grupo de psicanalistas que atendeu e pesquisou sujeitos autistas durante uma década, publicou seu Exploración del autismo, e nele buscou caracterizar os processos mentais autistas. Detectando como característica fundamental uma fragmentação do funcionamento psíquico, propõe a metáfora da fotografia cinemática de uma flor se abrindo como representação de um processo de desenvolvimento somente visível se assim detectado. Afirma que "a essência do processo mental autista propriamente dito é uma suspensão da vida mental"1, e defende que essa mente pode funcionar em grande velocidade, e possui

1. D. Meltzer et al. Exploración del autismo. Buenos Aires: Paidós, 1979, p. 23. 


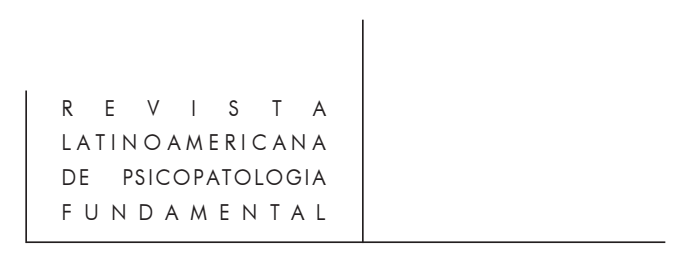

uma tal complexidade que perturba continuamente o terapeuta. Propõe a seguinte súmula das características mentais do autista:

... grande inteligência, sensibilidade ao estado emocional alheio, propensão ao sofrimento depressivo de forma massiva, mínimo sadismo e, em conseqüência, mínima persecutoriedade, ciúmes possessivos; sendo crianças de alta sensualidade em seu amor, passíveis de uma interminável repetição da alegria e triunfo pela posse do objeto. ${ }^{2}$

Para Meltzer e seus colaboradores, o processo fundamental de interrupção e desorganização da vida mental do autista ocorreria devido a um desmantelamento (dismantling), por meio do qual os eventos ou experiências se tornariam descontínuos e não mais conectáveis, por isso tornar-se-iam inaptos para o registro mnêmico, e não configurariam recordações, não permitindo, portanto, o aprender com as experiências.

Quando o self se desmantela em seus componentes sensoriais devido à suspensão da função egóica da atenção, um ego coerente cessa de existir temporariamente; cada fragmento ou componente se reduz a seu estado primitivo, dominado pelo id e por sua economia e dinâmica. Sugerimos que este primitivismo é essencialmente carente de atividade mental, desmentalizado. ${ }^{3}$

Essa descrição permite compreender os característicos sintomas autísticos de interromper a atenção continuamente, voltando-se para qualquer outro estímulo, interno ou externo, que tenha surgido. Desse modo o autista pode estar horas sentindo o interior de sua própria bochecha, depois prestar atenção a algo que lhe é proposto, depois ouvir subitamente um som externo, e assim sucessivamente. Dirige, portanto, de uma outra forma sua atenção, não efetuando os mesmos "recortes", a mesma seleção, que é o que empresta significado aos fatos. Meltzer dirá que, para o autista, os fatos "caem" simplesmente, não havendo o direcionamento ativo da atenção e da consensualidade que permitem adquirir a noção compartilhada da realidade. Essa abertura sensorial muitas vezes acarreta que o autista se sinta bombardeado pelos estímulos e, dinamicamente, implica uma tentativa de controle onipotente sobre os estímulos que nele incidem.

Um último item de especial significado é a distinção que Meltzer estabelece entre o autismo propriamente dito e os estados pós-autísticos, o que, embora sendo contestado por muitos especialistas, principalmente psiquiatras, é o que possibilita pensarmos em uma evolução para o autista.

É este igualmente o ponto de vista de partida do trabalho de uma das mais importantes pesquisadoras do autismo, a psicanalista Frances Tustin, cujos principais trabalhos são: Autism and Childhood Psychosis (1972), Autistic States in Children (1981), El cascarón protetor (1994).

2. Idem, p. 25.

3. Idem, p. 28. 


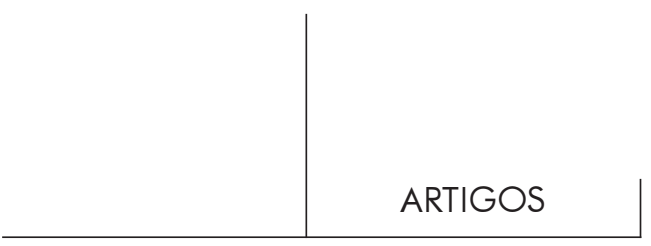

Frances Tustin trabalha a partir da suposição da existência de uma forma psicogênica de autismo, a qual não nega a possibilidade de formas orgânicas do mesmo quadro. Margareth Mahler (1958) e Donald Meltzer (1975) já haviam reconhecido a possibilidade de quadros autistas surgirem em resposta a mães deprimidas, com o bebê destruindo seu ego e todas as capacidades que dependessem de sua mãe para serem desenvolvidas.

As crianças autistas "desenvolveram, quando bebês, uma formação maciça de reações de evitação a fim de lidar com uma consciência traumática de separação física de suas mães"4. Tais reações ocorreram em uma época tão precoce do desenvolvimento, que esta criança ainda não conseguira uma adequada noção de constituição de si mesma e do outro, o que fez com que a perda de uma parte da mãe, o seio, fosse sentida como a perda de uma parte de si mesma. $\mathrm{O}$ "núcleo do self" ainda não se desenvolveu. O senso de "continuar a ser" (Winnicott) ainda não se estabeleceu no bebê. Ele viverá um temor de desintegração, de "cair infinitamente", de ter seus limites explodidos, de aniquilar-se. Tustin afirma que "esses terrores foram experimentados em um estado pré-verbal, pré-imagem e préconceitual." E acrescentará: "Eles significam que o desenvolvimento emocional e cognitivo da criança ou se desacelerou ou virtualmente parou." ${ }^{5}$ A pessoa como que se "congela".

A partir das próprias atividades físicas, e de suas reações auto-sensuais, a criança desenvolve uma carapaça, uma concha, que tanto a protege do mundo exterior quanto se constitui em uma barreira de acesso ao mundo. Nessa perspectiva, o autismo é considerado como uma defesa, defesa contra o excesso de estimulação não mediatizada pela mãe e, portanto, contra a confusão e a desintegração. Seu maior medo é "a perda do senso de existência"; seu desenvolvimento se paralisa em uma fase primitiva, onde os "sentimentos" ainda são vividos de uma forma física, mais táctil do que significável, mais identificado a "sensações". As dores, físicas e mentais, como a da separação da mãe, serão confundidas e equiparadas.

Tustin acentua que há um "dano à psique":

Esta criança está em choque. Ela se sente danificada, fraca e impotente. A reação, para contra-atacar isso, foi desenvolver práticas que lhe dessem ilusão de ser impenetrável, invulnerável, e estar no controle absoluto. ${ }^{6}$

O autismo preserva o estado da criança, em um estágio não-integrado, conservando "as feridas psíquicas da separação original" ". Frances Tustin propõe

4. F. Tustin. Barreiras autistas em pacientes neuróticos. Porto Alegre: Artes Médicas, 1990, p. 26.

5. Idem, p. 27

6. Idem, pp. 76 e 77.

7. Idem, p. 83 . 


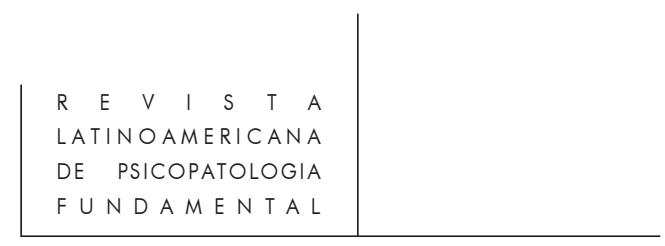

as noções de Objetos autistas e Formas autistas afirmando que eles são os sintomas que cobrem esse buraco, e ao mesmo tempo o mantém.

Outra importante contribuição nos chega pela grande psicanalista francesa Françoise Dolto. Trabalhando à partir de sua noção da imagem inconsciente do corpo, Dolto afirmará que esta é "onipresente nos psicóticos"8. Preocupada com o atendimento clínico, ela proporá que o psicanalista fique em "estado zero", permitindo que a criança, mediante essa suspensão do estado mental do psicanalista, possa aceder a uma ativação, somente dessa forma possibilitada: "É neste momento aí, insisto, que os psicóticos despertam à vida."

Atenta à verdade inerente ao trabalho psicanalítico, Dolto afirma:

$\mathrm{Eu}$ estou profundamente convencida de que não se pode fazer um tratamento de criança sem falar verdadeiramente o que se sente e o que se pensa estando-se com ela. Falar verdadeiro significa considerar aquele que está diante de si como um homem ou uma mulher que virá a ser, que é inteiramente linguagem em seu ser, tendo um corpo de criança, mas compreendendo tudo o que nós dissermos. ${ }^{10}$

A importância atribuída à linguagem faz remarcar que mesmo as crianças que não falam estão imersas na linguagem, pois "uma criança que não fala é inteiramente linguagem e está inteiramente na linguagem..."11

Para ela, o tratamento, tanto com as crianças como com os psicóticos e autistas, promove uma experiência contratransferencial radical, a de tornar ausente uma parte da imagem do corpo do psicanalista: "Nós somos literalmente desalojados de nós mesmos." 12

Jacques Lacan nos legou um importante trabalho, na forma de duas notas manuscritas, onde define as condições para a investigação da conexão entre os sintomas da criança e a rede de relações familiares onde ela está inserida:

$\mathrm{Na}$ concepção elaborada por Jacques Lacan, o sintoma da criança se situa de forma a corresponder ao que há de sintomático na estrutura familiar. O sintoma, aí está o fato fundamental da experiência analítica, se define nesse contexto como representante da verdade. O sintoma pode representar a verdade do casal familiar. Este é o caso mais complexo, mas também o mais aberto às nossas intervenções. ${ }^{13}$

8. F. Dolto e J.-D. Nasio. A criança do espelho. Porto Alegre: Artes Médicas, 1991, p. 11.

9. Idem, p. 23.

10. Idem, p. 49.

11. Idem, p. 52.

12. Idem, ibidem.

13. J. Lacan. "Duas notas sobre a criança". Ornicar? Revista do Campo Freudiano, no $³ 7$, abril-junho de 1986, p. 13. 


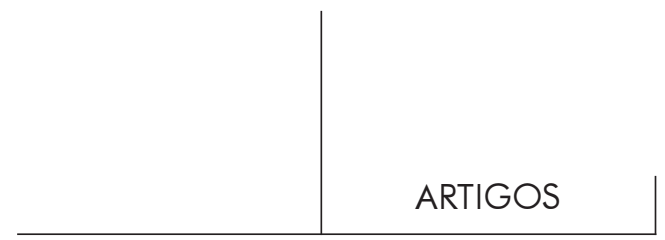

Partindo do referencial lacaniano, um trabalho fundamental para quem atua nessa área é o Psicanálise do autismo, do argentino Alfredo Jerusalinsky. Nele o autor vai indagar sobre a dinâmica da interação familiar que, desde as primeiras descrições do autismo, feitas por Kanner em 1943, vem sendo problematizada e discutida. Para Jerusalinsky não é a ausência da mãe o que vai contribuir para a emergência do sintoma autista, mas "a radical ausência do desejo materno em relação ao filho autista."14 Dirá ainda que "sempre encontramos perturbações intensas na ligação das mães com os filhos, concomitantes com os quadros de desconexão autística"15, ressaltando, contudo, poder tratar-se de formações reativas às características do filho.

Jerusalinsky é feliz ao adotar uma forma modificada da noção de séries complementares (Freud, 1917), para discutir a interação dos componentes biológicos, orgânicos, do autismo, e os componentes da estrutura familiar e da personalidade da mãe:

Os fatores que incidem na produção dos quadros de AIP (Autismo Infantil Precoce) obedecem a uma combinação de aspectos constitucionais da criança com aspectos compensatórios no exercício da função materna. Assim, podemos encontrar crianças sem anomalias orgânicas que justifiquem o AIP de que padecem, porém incluídas numa relação mãe-filho em que a perturbação da função materna constitui o fator eficaz. Em sentido contrário a esse tipo de caso, a extrema insuficiência de uma criança organicamente prejudicada pode tornar infrutíferos todos os esforços maternos compensatórios, dando igualmente como resultado um quadro de autismo. ${ }^{16}$

Insistindo em que não se está em busca de "culpados", Jerusalinsky estuda a função estrutural da mãe, não sua pessoa. Na gênese do autismo ele verá o "desequilíbrio do encontro do agente materno com a criança", independentemente do fator orgânico que, presente ou não, deve aparecer em uma "particular articulação psíquica"17. Assim, na amamentação, vai apresentar a complexidade de seu papel:

Este círculo maternal envolve outro ciclo com o que se superpõe e se intersecciona o ciclo de fome e dor, sucção-conforto, saciedade e satisfação. O bebê experimenta tudo isso com os olhos fixos no rosto da mãe, olhos que o engatam e rebocam até o universo no qual seu corpo, a boca e o leite adquirem sua inscrição: o universo simbólico. ${ }^{18}$

Estabelecidos estes parâmetros teóricos, vejamos agora as questões institucionais que devem ser levantadas para balizar o trabalho. Faremos referência a duas

14. A. Jerusalinsky. Psicanálise do autismo. Porto Alegre: Artes Médicas, 1984, p. 13.

15. Idem, p. 18.

16. Idem, pp. 19-20.

17. Idem, p. 31.

18. Idem, p. 41. 


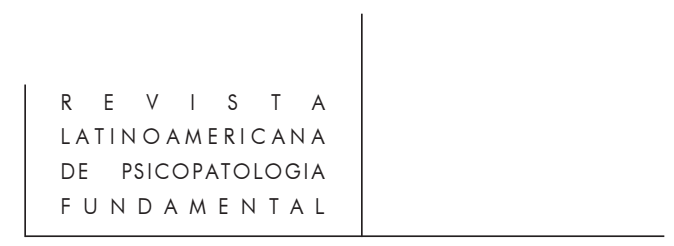

instituições congêneres, o "Lugar de Vida", da Universidade de São Paulo, e o NAICAP, do Hospital Phillipe Pinel do Rio de Janeiro.

Maria Cristina Kupfer, discorrendo sobre as crianças autistas, começa por afirmar: "Essas crianças precisam viver. Precisam de escolaridade, precisam frequientar uma escola." ${ }^{19}$ Esta, porém, precisa ser uma escola especial, não apenas a reprodução de um enquadre psicanalítico: "Uma instituição tem que ser uma ferramenta terapêutica, antes de tudo em sua montagem, em seu funcionamento." ${ }^{20}$, propondo que a circulação, a movimentação no interior da instituição, criem as ligações que faltam a essas crianças. Os agentes institucionais não funcionarão propriamente como psicanalistas, mas operarão uma "escuta flutuante" que permita a promoção de efeitos terapêuticos, e possibilite apostar que os autistas e psicóticos possam vir a construir laços sociais.

Já o Núcleo de Assistência Intensiva à Criança Autista e Psicótica, NAICAP, do Rio de Janeiro, parte da hipótese de que "existiriam condições de se propiciar às crianças autistas a construção de sua história ou a possibilidade de reconstrui-la, no caso das crianças psicóticas" 21. Visa a constituição de espaços e práticas "voltados para a singularidade de cada sujeito/criança, privilegiando suas particularidades, idiossincrasias e percurso próprio em direção à sua organização subjetiva" ${ }^{22}$.

E, para concluir, podemos nos alinhar a Alfredo Jerusalinsky:

O que seria uma instituição adequada, então? Uma instituição que tivesse uma profunda dúvida acerca de sua adequação ao fim que se propõe. Uma instituição que não tivesse nenhuma certeza e, portanto, que sua intervenção terapêutica não fosse um método, estivesse sujeita às vicissitudes que cada criança lhe apresentasse. ${ }^{23}$

A Escola Municipal do Autista de São José do Rio Preto utiliza os referenciais psicanalíticos fundamentalmente em quatro âmbitos de aplicação:

O primeiro âmbito é o da compreensão da criança, sua dinâmica psíquica. Outro é na compreensão das interações dela no mundo familiar e em seu cotidiano na escola, interagindo com os profissionais e as outras crianças. No âmbito do processo terapêutico, à medida que cada criança ou está em ludoterapia, ou em grupo terapêutico de orientação psicanalítica. Finalmente, a psicanálise comparece para a

19. M.C. Kupfer. "Psicose na infância - compreensão psicanalítica e intervenção". São Paulo (mimeo), p. 12.

20. Idem, p. 13 .

21. NAICAP. "Uma proposta de assistência intensiva à criança autista e psicótica”. Rio de Janeiro, 1993, (mimeo), p. 3.

22. Idem, p. 2.

23. A. Jerusalinsky. "Psicose e autismo na infância: uma questão de linguagem". Boletim - Psicose. Associação Psicanalítica de Porto Alegre, ano 4, no 9, 1993, p. 71. 


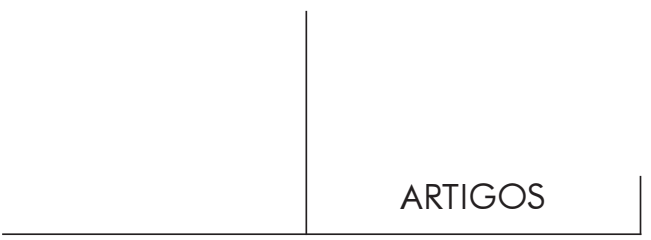

reflexão das questões institucionais, para a análise das contratransferências dos sujeitos envolvidos nos atendimentos e no ensino.

Entendemos que a instituição deva atuar como clínica e escola, e que sua ação frente aos sujeitos autistas e psicóticos deve partir do seu reconhecimento como sujeitos humanos, plenos em seu modo singular, com condições de desenvolvimento, de aquisições culturais, de aprendizagem, de produção, ao seu estilo, com suas particularidades. Concebemos nosso papel como o de promotores, promotores das melhores condições possíveis para a expressão de suas potencialidades, para a manifestação de seu mundo mental, para suas ações, suas interações, sua exploração do mundo e de si mesmos.

Procuramos criar uma estrutura multiprofissional que procurasse contemplar cada uma de suas possíveis necessidades. Procuramos auxiliá-los na área médica, sem convertê-los exclusivamente em casos médicos. Tentamos propiciar os cuidados de que possam necessitar com terapias físicas, fonoaudiológicas, e medicamentosas, com critério. As atividades educativas tentam fornecer-lhes as aprendizagens básicas, ao nível de vida prática e de vida diária, para favorecer sua adaptação ao mundo, porém preocupa-se em dotá-los de instrumentos para que essa não seja uma adaptação passiva, mas um processo ativo e criativo de aprendizagem. Os princípios construtivistas que adotamos são:

a) Considerar o aluno em suas necessidades pessoais, respeitando suas diferenças;

b) considerar o aluno em sua etapa de desenvolvimento;

c) valorizar focos de interesse como energizadores da aprendizagem; e

d) priorizar as ações do sujeito aprendente.

A partir da psicanálise e do construtivismo procuramos fazer com que o espaço escolar seja o território fértil para o crescimento e a expressão desses sujeitos, que serão ouvidos e com quem nos relacionaremos, convivendo e aprendendo.

Nosso objetivo é auxiliar o autista, mas não moldá-lo. É torná-lo ele mesmo. Aproximá-lo de si. Fazê-lo enunciar-se, produzir um discurso audível, antes de mais nada por ele mesmo, mas que possa comunicar. Comunicar-nos sua humanidade, sua singularidade, seu ser um. Introduzi-lo no mundo dos objetos compartilháveis, das trocas simbólicas, das produções, dos produtos, das coisas e dos homens. Da humanidade autoproduzida. Do conhecimento do seu Desejo. Da inquietação que faz as rodovias, os livros, as cidades, os lazeres, as guerras e as obras sublimes. Que faz o mundo e faz o homem. Será que esse intento de conhecer o autista não é a velha tarefa humana do conhecer-se a si próprio? 


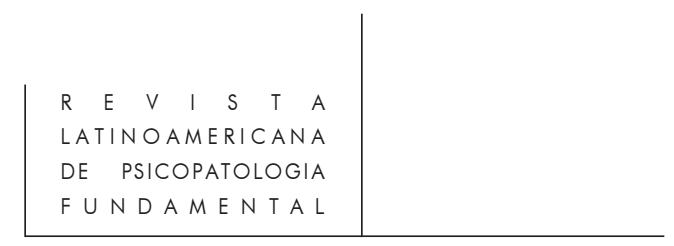

El presente articulo intenta articular una proposta para el trabajo clínico y pedagógico con sujetos autistas. Empieza por una discusión acerca de los tres imposibles asignados por Freud, a los cuales se suma la dimensión de la acción frente al autismo. Busca entonces caracterizar los conceptos psicoanalíticos instrumentales para una tal clínica, así como los referenciales constructivistas que embasan la acción pedagógica. Describe el trabajo desarrollado por el equipo multidisciplinario de la Escola Municipal do Autista de São José do Rio Preto, SP, y concluye con consideraciones acerca del sentido de trabajos de esa naturaleza.

Palabras llave: Psicoanálisis, educación, autismo, institución

Ce travail vise articuler un proposition pour le travail clinique et pédagogique avec les personnes autistes. Parte de cette discussion des les trois impossibles pointu par Freud, lequel s'accroîte la dimension de la action en face au l'autisme. Il caractérise les concepts de la Psychanalyse qui sont instrumentals pour cette clinique et les rapports construtivistes qui se base les actions pédagogiques. Il décrit le travail développé pour l'equipe multidiscipliner de la Escola Municipal do Autista de São José do Rio Preto, SP, et concluit avec considérations quant à le sens enveloppé en travaux de cette nature.

Mots clés: Psychanalyse, éducation, autisme, institution

This paper aims to articulate a proposition for the clinical and pedagogical work with autistic persons. It begins with the discussion about the three impossibilities presented by Freud, to which is added the dimension of the action towards the Austism. It characterizes the psychoanalysis' concepts which are useful for this clinical workd, and the construtivistic references that underlie the pedagogical actions. It describes the work developed by the multiprofessional team of the Escola Municipal do Autista de São José do Rio Preto, SP, and ends with some comments about the meaning of such works.

Key words: Psychoanalysis, education, autism, institution 